Revista de Ciencias Sociales - Número 65 (2014) - Páginas 13-45

El concepto hohfeldiano de derecho subjetivo

\title{
EL CONCEPTO HOHFELDIANO DE DERECHO SUBJETIVO
}

\section{THE CONCEPT OF SUBJECTIVE RIGHT OF HOHFELD}

\author{
MARÍA BEATRIZ ARRIAGADA CÁCERES* \\ Departamento de Teoría del Derecho \\ Universidad Diego Portales, Santiago de Chile \\ maria.arriagada@udp.cl
}

\section{Resumen}

En este artículo procuro mostrar que, tras la discusión teórica que aparentemente versa sobre el significado que debe atribuirse al concepto hohfeldiano de derecho subjetivo, se oculta el enfrentamiento de dos teorías diferentes acerca del fundamento extra-jurídico de los derechos subjetivos y que, en consecuencia, desde la perspectiva del modelo de análisis hohfeldiano de las posiciones jurídicas subjetivas, ninguna de estas teorías puede contar como una explicación de lo que los derechos subjetivos son, con independencia de las razones extra-jurídicas que justifican su otorgamiento.

\section{Palabras clave}

Derechos subjetivos, teoría de la voluntad, teoría del interés, Hohfeld.

\footnotetext{
* Licenciada en Derecho de la Pontifica Universidad Católica de Chile. Doctora en Derecho por Universidad de Chile. Artículo recibido el 28 de noviembre de 2014 y aceptado el 15 de diciembre de 2014.
}

Revista de Ciencias Sociales - Número 65 (2014) - Universidad de Valparaíso - ISSN 0716-7725-Valparaíso, Chile 


\begin{abstract}
In this paper, I shall intend to show that, behind the theoretical discussion that apparently relates to the meaning to be attributed to the Hohfeld's concept of subjective right, the confrontation of two different theories of extra-legal basis of subjective rights is hidden and that, consequently, from the perspective of the Hohfeld's analysis model of subjective legal positions, none of these theories can count as an explanation of what the individual rights are, regardless of the extra-legal reasons for their granting.
\end{abstract}

\title{
Keywords
}

Subjectives rights, the will theory, the interest theory, Hohfeld.

\section{Introducción}

Muy conocida es la influencia que, en el estudio y explicación de los llamados conceptos jurídicos fundamentales, ha tenido el modelo de análisis hohfeldiano de las posiciones jurídicas subjetivas ${ }^{1}$.

Pese a la claridad con la que Hohfeld distinguió las diversas posiciones jurídicas subjetivas a las que suele hacerse referencia mediante la expresión derecho subjetivo y de su esfuerzo por aclarar el significado específico que a dicha expresión corresponde, la discusión teórica en torno a este significado no ha cesado.

En las páginas que siguen, me propongo mostrar que tras la discusión teórica que aparentemente versa sobre el significado que debe atribuirse al concepto hohfeldiano de derecho subjetivo, se oculta el enfrentamiento de dos teorías diferentes acerca del fundamento extrajurídico de los derechos subjetivos y que, en consecuencia, desde la perspectiva del modelo de análisis hohfeldiano de las posiciones jurídicas subjetivas, ninguna de estas teorías puede contar como una explicación de lo que los derechos subjetivos son, con independencia de las razones extra-jurídicas que justifican su otorgamiento.

1. Sobre esta influencia, ver por ejemplo, MORESO, Josep Joan y VILAJOSANA, Josep María: Introducción a la teoría del derecho. Marcial Pons, Madrid, 2004. Pág.184.

Facultad de Derecho y Ciencias Sociales - Universidad de Valparaíso - Chile 
Para lograr este objetivo seguiré los siguientes pasos:

1. Caracterizaré brevemente el modelo de análisis hohfeldiano de las posiciones jurídicas subjetivas, poniendo de relieve que él se sustenta en dos importantes distinciones provenientes de la teoría analítica del derecho: "normas regulativas y normas de competencia" y "actos normativos y actos materiales".

2. Reseñaré la discusión que, en torno al significado que debe atribuirse al concepto de derecho subjetivo hohfeldiano, se ha producido en la teoría del derecho.

3. Argumentaré que las teorías que pretenden esclarecer este significado encubren la defensa de una razón extra-jurídica para el otorgamiento de derechos subjetivos.

4. Explicaré por qué, desde el punto de vista del fundamento del modelo de análisis hohfeldiano de las posiciones jurídicas subjetivas, ninguna de estas teorías puede contar como una explicación de lo que los derechos subjetivos son, con independencia de las razones extrajurídicas que justifican su otorgamiento.

\section{El modelo de análisis hohfeldiano de las posiciones jurídicas subjetivas}

El modelo de análisis hohfeldiano de las posiciones jurídicas subjetivas puede sintetizarse señalando que la expresión "derecho subjetivo" y la expresión "deber" suelen usarse para designar diferentes situaciones o posiciones jurídicas subjetivas que deben ser distinguidas. En un primer grupo de posiciones, la que propiamente debe ser denominada derecho subjetivo o pretensión se caracteriza porque su correlativo es un deber en sentido propio, y su opuesto un no derecho; mientras la situación de libertad o privilegio, se caracteriza porque su correlativo es un no derecho, y su opuesto un deber en sentido propio. En el segundo grupo de posiciones, la de potestad o competencia se caracteriza porque su correlativo es una sujeción, y su opuesto una incompetencia; mientras la situación de inmunidad se caracteriza porque su correlativo es una incompetencia, y su opuesto una sujeción ${ }^{2}$.

2. HOHFELD, Wesley: Conceptos jurídicos fundamentales. Fontamara, México D.F. 1992. (Trad. Genaro Carrió; original de 1913). Págs. 47-52, 67-68 y 81.

Revista de Ciencias Sociales - Número 65 (2014) - Universidad de Valparáíso - ISSN 0716-7725-Valparáiso, Chile 
El ejercicio explicativo de Hohfeld admite la denominación de "elucidación conceptual” o "análisis conectivo" porque la comprensión apropiada de cada concepto se obtiene captando sus relaciones con los demás conceptos del mismo sistema ${ }^{3}$. Ello justifica la utilidad que ha tenido y sigue teniendo como herramienta analítica.

Hay, sin embargo, un aspecto esencial de este modelo de análisis que no ha sido suficientemente resaltado. La identificación de las ocho diversas posiciones jurídicas subjetivas y su distribución en dos diferentes grupos, se sustenta en dos importantes distinciones que provienen de la teoría analítica del derecho: (i) normas regulativas y normas de competencia y (ii) actos materiales y actos normativos.

En sintonía con la sugerencia wittgensteiniana según la cual hay una captación de una regla que se manifiesta, de caso en caso de aplicación, en lo que llamamos "seguir la regla" y en lo que llamamos "contravenirla", el argumento mejor formulado en contra de los intentos de equiparar las normas de competencia con las normas regulativas se funda precisamente en la distinción de las consecuencias que se siguen de la observancia e inobservancia de unas y otras.

Me refiero al argumento hartiano según el cual, cuando se trata reglas que imponen deberes es posible distinguir claramente la regla que obliga a determinada conducta de la sanción establecida para el caso de su transgresión; mientras cuando se trata de una regla que confiere poderes no es lógicamente posible distinguir la regla (que

3. Sobre este tipo de análisis, ver STRAWSON, Peter: Análisis y metafísica. Paidós, Barcelona, 1997. (Trad. Nieves Guasch; original de 1992). Pág. 63. Sobre la caracterización de la explicación hohfeldiana como una análisis de este tipo, NINO, Carlos: Introducción al análisis del derecho. Astrea, Buenos Aires, 1980. Págs. 207-208 y CRUZ PARCERO, Juan Antonio: El lenguaje de los derechos. Ensayo para una teoría estructural de los derechos. Trotta, Madrid, 2007. Págs. 33-34 (nota No 19).

4. WITTGENSTEIN, Ludwig: Investigaciones filosóficas. Crítica, Barcelona, 2008 (Trad. Alfonso García Suárez y Ulises Moulines; original de 1953). Parágrafo 201. De otra forma no se explicaría que podamos reconocer cuando las normas han sido violadas y la capacidad que ellas tienen de cubrir nuevos casos; ver SEARLE, John: Actos de habla. Ensayo de Filosofía del Lenguaje. Cátedra, Madrid, 2007 (Trad. Luis Valdés Villanueva; original de 1969). Pág. 51.

Facultad de Derecho y Ciencias Sociales - Universidad de Valparaíso - Chile 
establece condiciones para la validez jurídica) de la nulidad; ésta es parte de la regla misma de este tipo de una manera distinta a como el castigo está ligado a una norma que impone deberes 5 . Por otra parte, las normas de competencia tampoco pueden ser asimiladas a las normas permisivas porque en el caso de estas últimas tampoco tiene sentido hablar de nulidad ${ }^{6}$.

Así, mientras de la observancia e inobservancia de las normas de competencia se sigue, siempre y respectivamente, la validez y la invalidez de las normas producidas en aplicación de aquellas normas, tales consecuencias no se siguen nunca de la respectiva observancia e inobservancia de las normas regulativas.

Hohfeld reconoce esta distinción cuando separa nítidamente el concepto de derecho subjetivo (también llamado pretensión) del concepto de potestad (también llamado competencia). Mientras la clave para dar con en el significado de la expresión "derecho subjetivo" es el "deber correlativo", el concepto de "potestad" es definido como la posición en la que se encuentra el individuo de cuya voluntad depende decisivamente la modificación de determinadas relaciones jurídicas ${ }^{8}$.

Un individuo tiene entonces un derecho subjetivo cuando, en virtud de una norma jurídica regulativa, otro u otros se encuentran a su respecto obligados a comportarse de cierta manera ${ }^{9}$. Un individuo tiene,

5. HART, H.L.A.: El concepto de derecho. Abeledo-Perrot, Buenos Aires, 2009 (Trad. Genaro Carrió; original de 1961). Págs.. 43-44. En el mismo sentido, BULYGIN, Eugenio: "Sobre las normas de competencia” En: Alchourrón, Carlos. y Bulygin, Eugenio: Análisis lógico y derecho. CEPC, Madrid, 1991 (original de 1988). Págs. 487-489 y 495-496. En contra, esto es, a favor de la posibilidad de asimilar las normas de competencia con las normas permisivas, ver por ejemplo, RAZ, Joseph: Razón práctica y normas. CEPC, Madrid, 1991 (Trad. Juan Ruiz Manero; original de 1975). Págs. 118-121 y NINO, Carlos, ob cit. Págs. 222-224.

6. ALCHOURRÓN, Carlos y BULYGIN, Eugenio: "Definiciones y normas". Pág. 462.

En: Análisis lógico y derecho, CEPC, Madrid, 1991 (original de 1983):

7. HOHFELD, Wesley, ob cit. Págs. 47-52.

8. Ibíd. Págs. 67-80.

9. En el mismo sentido, KELSEN, Hans: Teoría pura del Derecho (2a edición). Porrúa, México D.F., 1991. (Trad. Roberto Vernengo; original de 1960). Págs. $139-142$.

Revista de Ciencias Sociales - Número 65 (2014) - Universidad de Valparáíso - ISSN 0716-7725-Valparaíso, Chile 
en cambio, una potestad o competencia cuando, en virtud de una norma jurídica de competencia, tiene la posibilidad de realizar actos jurídicos que producen, modifican o eliminan normas jurídicas ${ }^{10}$.

La distinción entre normas regulativas y normas de competencia está íntimamente conectada con la distinción entre actos materiales y actos normativos.

Los actos materiales, naturales o informales pueden ser solamente supuestos de hecho de normas y se caracterizan porque producen dos tipos de efectos: (i) efectos de hecho desincentivados o incentivados por el derecho mediante prohibiciones y obligaciones, y (ii) efectos de derecho (sancionatorios o satisfactorios) preestablecidos por las normas que los regulan. A su turno, los actos normativos, artificiales o formales, no son simplemente supuestos de hecho de normas sino también actos aplicadores de normas. Y se caracterizan porque producen solamente efectos de derecho condicionados por las normas que lo prevén a la observancia de ciertas formas en el ejercicio de determinados poderes ${ }^{11}$.

En términos searlianos, los actos materiales son hechos brutos; su existencia no depende lógicamente de la existencia de ninguna regla; y los actos normativos son hechos institucionales; su existencia es

10. El concepto de competencia, tradicionalmente reservado para aludir al poder jurídico atribuido a los órganos públicos (legislativos, judiciales o administrativos) de producir normas generales o individuales, también comprende la capacidad que el orden jurídico confiere a los individuos de participar en la producción de normas generales o normas individuales; KELSEN, Hans, Teoría pura del derecho, cit. Págs. 158-161 y 151-157. De hecho, en el discurso de la teoría del derecho, el término "competencia" no está generalmente reservado para los órganos jurídicos; ver por ejemplo, ROSS, Alf: “Sobre los conceptos de 'Estado' y 'Órganos del Estado' en Derecho Constitucional”. En: El concepto de validez y otros ensayos. Fontamara, México, 1991 (Trad. Eduardo A. Vásquez; original de 1961). Págs 77-78; CRUZ PARCERO, Juan Antonio: El lenguaje de los derechos, cit. Págs. 35-36; ATIENZA, Manuel y RUIZ MANERO, Juan: Las piezas del derecho. Ariel, Barcelona, 2004.

Pág. 83. Incluso el propio Hohfeld admite que las potestades del agent son comparables a las de los funcionarios públicos; ver HOHFELD, Wesley, ob cit. Pág. 71.

11. FERRAJOLI, Luigi: Principia iuris. Teoría del derecho y de la democracia. Trotta, Madrid, 2011 (Trad. Perfecto Ibáñez, Juan Carlos Bayón, Marina Gascón, Luis Prieto Sanchís y Alfonso Ruiz Miguel; original de 2007). Págs. 464-465.

Facultad de Derecho y Ciencias Sociales - Universidad de Valparaíso - Chile 
lógicamente dependiente de la existencia de las llamadas reglas constitutivas ${ }^{12}$.

El modelo de análisis hohfeldiano permite captar bien esta distinción, así como su relación con la de "normas de competencia y normas regulativas":

i) Mientras las relaciones de "potestad-sujeción" se refieren siempre a la posibilidad de realizar actos normativos en aplicación de normas de competencia, una relación de "inmunidad-incompetencia" connota la imposibilidad de realizar tales actos porque se fundamenta en la ausencia de normas de competencia.

ii) Mientras las relaciones de "derecho-deber" pueden referirse a la exigencia de realizar o no realizar actos materiales que son supuestos de hecho de normas regulativas ${ }^{13}$, una relación de "libertad-no derecho" puede connotar la inexistencia de la exigencia de realizar este tipo de actos pues se fundamenta en la ausencia de normas de regulativas.

\section{La discusión teórica sobre el concepto hohfeldiano de derecho subjetivo}

Pese a claridad con la que Hohfeld definió el concepto de derecho subjetivo, el sentido que debe atribuirse al mismo ha sido objeto de una interminable disputa.

Como sintetiza Finnis, el debate de la teoría jurídica sobre la adecuada explicación de los derechos y de la lógica de su lenguaje, ha sido provocado por dos problemas diferentes, cuyas respuestas, opuestas

12. SEARLE, John: Actos de habla, cit. Págs. 58-61 y La construcción de la realidad social. Paidós, Barcelona, 1997 (Trad. Antoni Domènech; original de 1995). Págs. 44-46.

13. En tanto la posición pasiva denominada "deber" a menudo consiste en una exigencia de realizar o no una determinada conducta material.

Revista de Ciencias Sociales - Número 65 (2014) - Universidad de Valparáíso - ISSN 0716-7725-Valparaíso, Chile 
entre sí, se superponen como si hubiera un único problema que provocara las tesis opuestas ${ }^{14}$.

El primer problema sería técnico y consistiría en la necesidad de estipular al menos un postulado definicional —que Hohfeld habría omitido - para responder a las siguientes preguntas: (i) ¿Cuándo diremos que hay un "derecho-exigencia" (pretensión) correlativo a un deber? y (ii) ¿En quién reside este derecho-exigencia? La primera respuesta es que hay un "derecho-exigencia" correlativo al deber de otro si, y solo si, hay una persona determinable en cuyo beneficio ha sido impuesto el deber, en el sentido de ser el destinatario de la ventaja (presumible) derivada del cumplimiento del deber; y esa persona tiene el "derecho-exigencia" correlativo al deber. La respuesta alternativa es que hay un "derecho-exigencia" si, y solo si, hay alguna persona que tiene el poder de entablar una apropiada acción legal de reparación en el caso de que quien tiene el deber deje de cumplirlo. A juicio de Finnis, ninguna de estas dos respuestas estaría reflejada de manera consistente en el discurso jurídico ${ }^{15}$.

14. FINNIS, John: Ley natural y derechos naturales. Abeledo Perrot, Buenos Aires, 2000 (Trad. Cristóbal Orrego; original de 1980). Pág. 231.

15. Si un ordenamiento dispone que cuando $\mathrm{B}$ y $\mathrm{C}$ suscriben un contrato por el que $\mathrm{C}$ pagará una suma de dinero a $\mathrm{A}, \mathrm{A}$ no tiene ningún poder para obtener el cumplimiento forzado del deber de $\mathrm{C}$ o para entablar una acción de reparación en caso de que $\mathrm{C}$ no cumpla. Según la primera aproximación, el sentido de este precepto legal podría expresarse diciendo que, bajo un contrato de ese tipo, A tiene un derechoexigencia correlativo al deber de C, pero él mismo no puede obtener la satisfacción forzada de su derecho-exigencia ni hacerlo valer legalmente. Según la segunda aproximación, tendríamos que decir que A simplemente no tiene derechos derivados del contrato celebrado en su beneficio. Según Finnis, los juristas ingleses oscilan entre estas dos aproximaciones. Con todo, Finnis reconoce que, según la primera aproximación, podría agregarse que $\mathrm{B}$ tiene también un derecho-exigencia correlativo al deber de $\mathrm{C}$ puesto que siempre (presumiblemente) va en beneficio del destinatario de la promesa el que el promitente haga honor a su promesa aun cuando los beneficios materiales de la misma vayan a alguien distinto de su destinatario. De este modo, formalmente $\mathrm{C}$ tendría un deber legal que comprende dos deberes hohfeldianos de idéntica forma, con A y con B, pero B, a diferencia de A, puede obtener la satisfacción forzada de su derecho-exigencia; Ibíd. Págs. 231-232.

Facultad de Derecho y Ciencias Sociales - Universidad de Valparaíso - Chile 
El segundo problema sería filosófico y correspondería a la siguiente pregunta: ¿Cuál es, si lo hay, el principio subyacente que unifica los diversos tipos de relaciones respecto de las cuales razonablemente se dice que tienen que ver con los derechos? Y las principales respuestas correrían paralelas a las dos precedentes. De un lado, se sostiene que los derechos en todas sus formas son beneficios garantizados a las personas por reglas que regulan las relaciones entre esas personas y otras personas sometidas a reglas. Del otro lado, se afirma que todo el sentido y la característica unificadora de las reglas que implican o crean derechos, estriba en que tales reglas específicamente reconocen y respetan la elección propia de las personas ${ }^{16}$.

El primer punto de vista es propio de la llamada "teoría del interés", también conocida como "teoría de los beneficios". De acuerdo con ella, un individuo A tiene un derecho subjetivo correlativo al deber de otro individuo B, cuando el deber de B ha sido impuesto en interés o en beneficio de A. Paralelamente, los derechos son considerados intereses o beneficios garantizados a las personas por reglas.

El segundo punto de vista es propio de la llamada "teoría de la voluntad", también denominada "teoría de la decisión" o "teoría de las elecciones jurídicamente respetadas". De acuerdo con ella, un individuo A tiene un derecho subjetivo correlativo al deber de otro individuo B, cuando A tiene el poder de entablar una apropiada acción legal de reparación en el caso que $\mathrm{B}$ deje de cumplir con su deber. Paralelamente, se considera que las reglas que confieren derechos reconocen y respetan las elecciones de las personas.

Uno de los más destacados exponentes de la teoría de la voluntad es H.L.A Hart quien, ya en el primero de los trabajos que dedicó a los derechos subjetivos, sostuvo que la expresión "derecho subjetivo", en el primer sentido distinguido por Hohfeld (correlativo al deber), podía ser elucidada en los siguientes términos:

“ 1 . Un enunciado de la forma ' $\mathrm{X}$ tiene un derecho subjetivo' es verdadero si se satisfacen las condiciones siguientes: a) existe un sistema jurídico; b) conforme a una regla o reglas del sistema,

16. Ibíd. Págs. 232-233.

Revista de Ciencias Sociales - Número 65 (2014) - Universidad de Valparáíso - ISSN 0716-7725-Valparáiso, Chile 
otra persona Y está, en las circunstancias que han acaecido, obligada a hacer o a omitir alguna acción; c) el orden jurídico hace depender esta obligación de la elección de $\mathrm{X}$ o de alguna otra persona autorizada a actuar en su nombre, de tal modo que o bien Y está obligado a realizar a omitir cierta acción sólo si X (o su representante) así lo quiere, o bien sólo mientras $\mathrm{X}$ (o dicho representante) no quiera otra cosa. 2) Un enunciado de la forma 'X tiene un derecho subjetivo' se usa para extraer una conclusión de derecho en un caso particular que cae bajo tales reglas" 17 .

De acuerdo con Hart, todos los sentidos de derecho subjetivo distinguidos por Hohfeld pueden elucidarse a partir de la idea que, en todos ellos, el derecho reconoce específicamente la elección de un individuo ${ }^{18}$. Pero en lo que ahora interesa, el signo distintivo de un derecho subjetivo en sentido estricto sería que el derecho (objetivo) da efecto a la elección de un individuo dirigida a que otro haga u omita alguna acción ${ }^{19}$.

Más $\operatorname{tarde}^{20}$, y en la misma línea, Hart critica directamente la teoría opuesta, que considera a los derechos como beneficios aduciendo dos razones:

La primera es que el hecho que alguien sea beneficiario o el pretendido beneficiario de una obligación no es una condición suficiente para afirmar que tiene un derecho. Lo característico de un derecho sería que éste le otorga a su titular el control exclusivo, más o menos extenso, sobre la obligación de otra persona, de modo que en el área de conducta cubierta por el deber, el individuo que tiene el derecho y a quien la obligación es debida, es un soberano a pequeña escala ${ }^{21}$.

17. HART, H.L.A.: "Definición y teoría en la ciencia judicial". En: Derecho y moral. Contribuciones a su análisis. Depalma, Buenos Aires, 1962 (Trad. Genaro Carrió; original de 1953). Págs. 117-118. Ver también nota No 14 del mismo trabajo.

18. Ibíd: 118 (nota $\mathrm{N}^{\circ} 4$ ).

19. Ibíd; 119 (nota $\mathrm{N}^{\circ} 4$ ).

20. HART, H.L.A.: "Legal Rights". En: Essays on Bentham. Studies in Jurisprudence and Political Theory. Oxford University Press, New York, 1982.

21. Ibíd. Págs. 183-184.

Facultad de Derecho y Ciencias Sociales - Universidad de Valparaíso - Chile 
La segunda razón es que el hecho que alguien sea beneficiario o se le pretenda beneficiar con el cumplimiento de una obligación no es una condición necesaria para tener un derecho ya que los contratos suelen hacerse para beneficiar a un tercero que no puede exigir el cumplimiento de la obligación, renunciar a dicho cumplimiento, ni liberar a los obligados de dicho cumplimiento. En esta situación, el tercero es un beneficiario desde que el incumplimiento del contrato constituye un perjuicio directo para él pero, al carecer de control sobre la obligación de otro, no tiene un derecho. A su turno, el contratante que, por tener dicho control, sí tiene un derecho, no es la persona a quien el contrato pretende beneficiar ${ }^{22}$.

La conclusión obtenida es que para que exista un derecho subjetivo no es suficiente ni necesario que el titular del derecho sea el beneficiario de la obligación. Es suficiente y necesario que tenga al menos algún grado control sobre la obligación correlativa ${ }^{23}$.

En el lado opuesto, uno de los más importantes representantes de la denominada "teoría del interés" es uno de los discípulos de Hart: Neil MacCormick. De hecho es muy conocida la crítica que este autor dirige a la teoría de la voluntad utilizando el argumento de que los niños tienen derechos ${ }^{24}$.

\section{Ibíd. Pág. 187. \\ 23. Ibíd. Pág. 188.}

24. MACCORMICK, Neil: "Los derechos de los niños: una prueba de fuego para las teorías de los derechos". En: Anuario de Filosofía del Derecho, N 5, Madrid, 1988. (Trad. Mercedes Carreras y A. Luis Martínez-Pujalte; original de 1975). Págs. 293-305. Raz, también discípulo de Hart, es otro destacado exponente de la teoría del interés, en la medida en que su propuesta, como el mismo lo admite, no es más que una versión refinada de la misma, que se caracteriza por discutir la idea que el conflicto entre el bien individual y el general es central para la comprensión de los derechos. En su opinión, los intereses de los titulares constituyen sólo una parte de la razón que justifica muchos de los derechos. También suelen ser relevantes: (i) los intereses de los demás (por ejemplo, en el caso del derecho de una mujer embarazada condenada a muerte a no ser ejecutada sino después de que el niño haya nacido), y (ii) el interés general (como en el caso de los derechos civiles y políticos en las democracias liberales); ver RAZ, Joseph: La ética en el ámbito público. Gedisa, Barcelona, 2001 (Trad. Juan Ruiz Manero; original de 1994). Págs. 57-68.

Revista de Ciencias Sociales - Número 65 (2014) - Universidad de Valparaíso - ISSN 0716-7725-Valparáís, Chile 
La incapacidad de esta teoría para justificar estos derechos probaría que ella es insostenible en cualquiera de sus formas por considerar como constitutivo de un derecho aquello que no es más que un accesorio: la opción con la que cuenta su titular. La presunción de que las personas son los mejores jueces acerca de lo que es bueno para ellos no debería ser extendida a los niños y, por tanto, en este caso, no corresponde considerar que los derechos de los niños llevan consigo la opción de su renuncia o ejercicio. Es cierto que, salvo en casos tales como el de los niños o los enfermos mentales, el titular de un derecho legal tiene normalmente la facultad atribuida por ley de decidir, en una situación dada, si hace o no uso del derecho exigiendo el cumplimiento por la otra parte del deber correspondiente. Esto es particularmente claro en el caso de los derechos privados, donde la ruptura de un deber correlativo hace surgir un "derecho al remedio" que el titular puede ejercer o no según le parezca. A juicio de MacCormick, aunque esto sea cierto e importante, las facultades de ejecución y de renuncia están esencialmente subordinadas a los derechos, y por tanto, no son constitutivas de ellos ${ }^{25}$.

La discusión puede matizarse desde el momento en que el propio Hart admite que el poder de control o la posición de soberanía que, en su opinión, es característica de los derechos subjetivos no es igual en todos los casos. No todos los beneficiarios o todos aquellos a quienes se pretende beneficiar con las obligaciones jurídicas de otros se encuentran en una única posición de soberanía en relación con la obligación ${ }^{26}$.

En este sentido, Hart destaca, por una parte, los casos en que no existe el poder de liberar al deudor del cumplimiento de ciertas

25. MACCORMICK, Neil: "Los derechos de los niños”, cit. Págs. 295 y 303-304.

26. La mayor medida de control comprendería tres elementos distinguibles: (i) el titular del derecho puede renunciar o extinguir la obligación o dejarla existente; (ii) puede, después del incumplimiento o amenaza de incumplimiento, dejar de exigir el cumplimiento o exigirlo demandando una compensación o, en ciertos casos, el aseguramiento de su cumplimiento mediante una medida precautoria u otra orden judicial destinada a que se deje de incumplir o no se incumpla en el futuro; y (iii) puede renunciar o extinguir la obligación de indemnizar a que el incumplimiento da lugar; HART, H.L.A.: "Legal Rights”, cit., Págs. 183-184.

Facultad de Derecho y Ciencias Sociales - Universidad de Valparaíso - Chile 
obligaciones aun cuando el titular del derecho suscriba un acuerdo en virtud del cual renuncia a demandar por el incumplimiento y, por otra parte, el caso de la protección del derecho penal, donde las personas no tienen el poder de liberar a nadie de sus obligaciones pues, aunque en teoría tengan el derecho de accionar junto con cualquier persona, no tienen el poder único de determinar si las obligaciones de la ley criminal deben ser o no cumplidas. Aunque aclara que la circunstancia de que el carácter absoluto de ciertas obligaciones determine que sus beneficiarios carezcan de poderes de control respecto de su cumplimiento, como consecuencia de lo cual es posible discutir que ellos sean titulares de derechos correlativos, no implica que sólo las obligaciones (relativas) del derecho civil tengan derechos correlativos ${ }^{27}$.

En este contexto, argumenta que, dentro de las funciones que el Estado cumple en relación con el bienestar, se contemplan obligaciones jurídicas de proporcionar, a quienes reúnan ciertas condiciones, beneficios que pueden tener la forma de pagos en dinero (por ejemplo, asistencia pública, seguro de desempleo, subsidios a la agricultura) o suministro de bienes o servicios (por ejemplo en relación con el cuidado de la salud). En tales casos sería perfectamente común y natural afirmar que los individuos que han satisfecho las condiciones requeridas tienen "derecho" a tales beneficios. Y a pesar de que normalmente esta no sería una hipótesis en la cual los beneficiarios de estas obligaciones tendrían sobre las mismas el tipo de control que es distintivo de los derechos que son correlativos a obligaciones, en la mayoría de estos casos se presentan dos características que permiten vincularlos a los casos paradigmáticos de derechos correlativos a obligaciones del derecho civil $^{28}$.

La primera de ellas es que, por regla general, la obligación de proporcionar beneficios es condicional, en el sentido que depende de que ella sea demandada por los beneficiarios, quienes entonces son libres de hacerlo o no. En este sentido, aun cuando estos beneficiarios no tengan el poder de renunciar o de extinguir la obligación, tienen el

\footnotetext{
27. Ibíd. Págs. 184-185.

28. Ibíd. Págs. 185-186.
}

Revista de Ciencias Sociales - Número 65 (2014) - Universidad de Valparáíso - ISSN 0716-7725-Valparaíso, Chile 
poder de sustituir una obligación condicional que no requiere cumplimiento en el presente por una incondicional que sí lo requiere mediante la presentación de una demanda; como consecuencia, enfatiza Hart, tendrían una opción. La segunda característica es que, aunque el incumplimiento de tales obligaciones puede no dar lugar a obligaciones secundarias de indemnización, en muchos de tales casos se ha avanzado en el sentido que si el beneficiario ha sufrido algún daño, se encuentra en una posición que lo legitima para que, con motivo de su solicitud, un tribunal pueda dictar una orden dirigida a que el organismo oficial pertinente cumpla con su obligación o deje de incumplirla ${ }^{29}$.

Estas dos características permitirían diferenciar a los beneficiarios de estas obligaciones de los beneficiarios de las obligaciones ordinarias del derecho penal a quienes, en cambio, no cabría considerar como titulares de derechos subjetivos. Esto se explica porque mientras la descripción del derecho penal generalmente podría efectuarse exclusivamente en términos de obligaciones, una explicación semejante de las obligaciones estatales relativas al bienestar oscurecería estas dos importantes características. La circunstancia de que el cumplimiento de estas obligaciones se haga depender de la demanda de sus beneficiarios y de que éstos dispongan de los medios para hacerlas cumplir, determina que la posición jurídica de estos sujetos sea un foco de atención que requiere de una descripción separada de la que se hace respecto de las obligaciones que los benefician ${ }^{30}$.

Se debe notar, sin embargo, que la posibilidad de considerar a estos beneficios sociales como derechos subjetivos está, como el propio Hart lo admite, subordinada a la presencia de las dos características apuntadas. Como consecuencia, la falta de ellas sólo dejaría en pie a los beneficios en tanto contenido de obligaciones estatales y no a los derechos subjetivos.

En contraste, de acuerdo con MacCormick, cuando una parte debe actuar o abstenerse de actuar de algún modo y el incumplimiento de este deber constituye un ilícito en contra de la persona afectada, esta

29. Ibíd: 186.
30. Ídem.

Facultad de Derecho y Ciencias Sociales - Universidad de Valparaíso - Chile 
última tiene derecho a que la primera no actúe de esa manera. Una tiene el derecho y la otra el deber correspondiente ${ }^{31}$.

Desde este punto de vista, al considerar como una parte esencial de los derechos algo que es normalmente accesorio, la teoría de la decisión estaría confundiendo la parte con el todo. Al definirlos como facultades o potestades en cuya virtud su titular puede decidir discrecionalmente sobre los deberes de otro, estaría ignorando el aspecto pasivo de los derechos. Pues cuando los derechos tienen relación con la conducta de personas distintas a su titular asumen una forma puramente pasiva. Si ellos vienen acompañados de derechos activos de decisión, sus titulares serán libres para decidir de modo completamente discrecional si van a exigir o no que otros respeten sus derechos pasivos, de suerte que nadie puede tener un derecho pasivo a que ellos se abstengan de esta decisión ${ }^{32}$.

De este modo, y pese a los matices que puedan introducirse, el foco de la discusión continúa siendo si los derechos subjetivos pueden considerarse intereses (beneficios) o bien poderes de decisión (elecciones) protegidos por el derecho, en cuyo caso las facultades con que a menudo cuentan los titulares de aquéllos forman parte del concepto mismo de derecho subjetivo.

\section{Las auténticas razones de la controversia}

Frente a la discusión recién reseñada parece imponerse la claridad con la que Hohfeld definió el concepto de derecho subjetivo:

Si reconocemos, como tenemos que hacerlo, el uso muy amplio y sin discriminaciones que se hace de la palabra 'derecho' (subjetivo) cabe preguntar qué indicio o pista hallamos en el lenguaje jurídico ordinario que sugiera una limitación de ella en la dirección de un significado definido y apropiado. Esa pista o indicio consiste en el 'deber' correlativo, porque no cabe duda

31. MACCORMICK, Neil, Instituciones del derecho. Marcial Pons, Madrid, 2011. (Trad. Fernando Atria y Samuel Tschorne; original de 2007). Págs. 155-156.

32. Ibíd. Págs. 156-166.

Revista de Ciencias Sociales - Número 65 (2014) - Universidad de Valparáíso - ISSN 0716-7725-Valparaíso, Chile 
de que aun aquellos que emplean la expresión y el concepto de la manera más amplia posible están habituados a pensar en 'deber' como su correlativo invariable" ${ }^{33}$.

El significado que Hohfeld atribuye a la expresión derecho subjetivo coincide con el significado del "derecho subjetivo reflejo" definido por Kelsen quien, junto con afirmar que un derecho subjetivo no es otra cosa que el reflejo de una obligación (positiva o negativa) de otro u otros ${ }^{34}$, enfatiza que, en esta definición, está implicado el rechazo tanto de la teoría del interés como de la teoría de la voluntad ${ }^{35}$. De hecho, ya en su primera obra Kelsen argumentaba que cada una de estas teorías, así como cualquier combinación de ambas incurrían en el mismo tipo de error al intentar poner de manifiesto lo que el derecho (objetivo) protege o reconoce (un factor de carácter sustancial, psíquico), en lugar de la protección (la forma) que interesa al jurista ${ }^{36}$.

Para Hohfeld (tanto como para Kelsen) los derechos subjetivos no son entonces derechos activos (a hacer algo) sino derechos pasivos ${ }^{37}$ que, conferidos por normas regulativas, obligan a uno o más individuos a realizar una acción o una abstención.

\section{HOHFELD, Wesley, ob. cit. Pág. 49.}

34. En esta relación sólo es "sujeto" el individuo obligado porque el individuo en cuyo respecto se ha constituido la obligación y ha de efectuarse la conducta obligatoria es considerado tan objeto de esa conducta como el animal, la planta o el objeto inanimado en cuyo respecto algunos hombres están obligados a comportarse de determinada manera; KELSEN, Hans, Teoría pura del derecho, cit. Págs. 139-142. Sobre la coincidencia entre el concepto kelseniano de derecho reflejo y el concepto hohfeldiano de derecho subjetivo, ver por ejemplo CRUZ PARCERO, Juan Antonio; El lenguaje de los derechos, cit. Pág. 37.

35. KELSEN, Hans, Teoría pura del derecho, cit. Págs. 145-150.

36. KELSEN, Hans: Problemas capitales de la teoría jurídica. Porrúa, México D.F., 1987. (Trad. Wenceslao Roces; original de1923). Págs. 510 y 539.

37. Tener un derecho pasivo significa tener derecho a que se respete una situación o a recibir algo por parte de otro; CRUZ PARCERO, Juan Antonio: El lenguaje de los derechos, cit. Pág. 24.

Facultad de Derecho y Ciencias Sociales - Universidad de Valparaíso - Chile 
Esta aclaración permite responder a una de las críticas más relevantes que han sido formuladas al modelo de análisis hohfeldiano de los derechos subjetivos.

Se ha sostenido que uno de los postulados fundamentales de este modelo sería que afirmar un derecho es afirmar una relación de tres términos entre una persona determinada, una descripción de un tipo de acto y otra persona determinada ${ }^{38}$. El problema de este "modelo relacional simple" (consistente en analizar los derechos como una relación entre dos sujetos respecto a un objeto) sería que sólo es útil para los llamados derechos in personam y no, en cambio, para los derechos in rem $^{39}$.

A ello puede responderse enfatizando, como hace Kelsen, que cuando para mantener en pie la distinción entre derechos reales y personales, se definen los primeros como el derecho de un individuo a disponer de cualquier manera de determinada cosa, se pasa por alto que ese derecho no consiste sino en la obligación de todos los demás individuos a consentir en esos actos de disposición; es decir, en la obligación de no impedir esos actos, o de no intervenir en ellos. Desde este punto de vista, un derecho real no es realmente un derecho sobre una cosa sino un derecho con respecto de personas ${ }^{40}$. Pues la expresión derecho subjetivo puede ser usada en el sentido que un determinado individuo está jurídicamente obligado $-\mathrm{o}$, inclusive, que todos los individuos están jurídicamente obligados - a actuar de determinada manera con respecto del individuo que tiene el derecho subjetivo ${ }^{41}$.

38. FINNIS, John, ob cit. Pág. 228.

39. CRUZ PARCERO, Juan Antonio: "Leones, lenguaje y derechos. Sobre la existencia de los derechos sociales (Réplica a Fernando Atria). En: Doxa, Discusiones: Derechos sociales, $\mathrm{N}^{\circ} 4$ 2004. Págs. 74-76; ver también nota $\mathrm{N}^{\circ} 1$ de ese mismo trabajo.

40. KELSEN, Hans: Teoría pura del derecho, cit. Pág. 143.

41. Por ello es que Kelsen critica que el “ejercicio" de los derechos sea identificado con la conducta correspondiente del individuo en cuyo respecto existe la obligación; KELSEN, Hans: Teoría pura del derecho, cit. Págs. 139-140.

Revista de Ciencias Sociales - Número 65 (2014) - Universidad de Valparáíso - ISSN 0716-7725-Valparáiso, Chile 
Algo distinto a tener un derecho subjetivo hohfeldiano (o un derecho reflejo kelseniano) es que al titular de un derecho de este tipo se le confiera, además, el poder de poner en movimiento, mediante una acción, el procedimiento destinado a reconocer el incumplimiento de la obligación por el deudor, y por tanto, el poder de participar en la producción de la norma jurídica individual de la sentencia judicial en la que se estatuye una sanción concreta por dicho incumplimiento. En esta situación, el individuo tiene lo que Kelsen llama un "derecho subjetivo en sentido técnico" ${ }^{42}$; un derecho igualmente pasivo que, a diferencia del simple derecho reflejo, se encuentra judicialmente garantizado ${ }^{43}$.

La diferencia entre la reconstrucción de los derechos subjetivos que hace la teoría de la voluntad y la kelseniana del derecho subjetivo en sentido técnico reside, como observa Cruz Parcero, en que mientras la teoría de la voluntad se centra en el tipo de control que tiene el titular del derecho respecto de la posición de la otra parte y el control que tiene para demandarlo en caso de que así lo elija, la teoría kelseniana (debiera decir la reconstrucción del derecho en sentido técnico que hace Kelsen), no pone énfasis en la voluntad del titular, es decir, en su capacidad de elegir qué va a hacer, sino tan sólo en la existencia de la norma que lo faculta, que le confiere un poder jurídico que se traduce en una acción judicial para exigir frente al Estado el cumplimiento del deber ${ }^{44}$.

Compárese, por ejemplo, el concepto kelseniano de derecho subjetivo en sentido técnico con el concepto hartiano de derecho subjetivo.

42. Ibíd. Págs. 146-149 y 152.

43. Sobre la distinción entre los derechos y su garantía judicial, ver por ejemplo ALEXY, Robert: Teoría de los derechos fundamentales. CEPC, Madrid, 2007 (Trad., Carlos Bernal Pulido; original de 1984). Pág. 456 y GUASTINI, Riccardo: Distinguiendo. Estudios de teoría y metateoría del derecho. Gedisa, Barcelona, 1999 (Trad. Jordi Ferrer; original de 1996). Pág. 185.

44. CRUZ PARCERO, Juan Antonio: El lenguaje de los derechos, cit. Pág. 32.

Facultad de Derecho y Ciencias Sociales - Universidad de Valparaíso - Chile 
Un derecho subjetivo en sentido técnico es un derecho reflejo provisto del poder jurídico de poner en movimiento, mediante una acción, el procedimiento destinado a reconocer la falta de cumplimiento de la obligación por el deudor, esto es, el poder jurídico de participar en la producción de la norma jurídica individual de la sentencia judicial en la que se estatuye una sanción concreta por dicho incumplimiento ${ }^{45}$.

El derecho subjetivo en sentido técnico, tanto como el simple derecho reflejo, se vincula con el concepto de sanción. Un individuo tiene un derecho subjetivo reflejo cuando a su respecto otro, otros, o todos los otros individuos están jurídicamente obligados a actuar de determinada manera ${ }^{46}$. Y decir que un individuo está obligado a determinada conducta, significa que en el caso de un comportamiento contrario, debe producirse una sanción. Su obligación es la norma que requiere esa conducta en tanto enlaza a la conducta contraria una sanción ${ }^{47}$.

Las sanciones son, según Kelsen, actos coactivos (actos que ha de cumplirse aun contra la voluntad del afectado por ellos, y en caso de oposición, recurriendo a la fuerza física) estatuidos como reacción contra una acción u omisión determinada por el orden jurídico. Y si bien en los órdenes jurídicos estatales ellas aparecen en dos formas diferentes (como sanción penal o pena y como sanción civil o ejecución forzosa de bienes), ambas consisten en irrogar coactivamente un mal, o expresado negativamente, en la privación coactiva de un bien ${ }^{48}$.

45. En el ejercicio de este poder jurídico, el individuo es "sujeto" de un derecho diferente la obligación jurídica; KELSEN, Hans: Teoría pura del derecho, cit. Págs. 146-149 y 152.

46. Ibíd. Pág. 139.

47. Ibíd. Pág. 140. "Enunciar que un individuo está jurídicamente obligado a determinada conducta, es lo mismo que afirmar que una norma jurídica ordena determinada conducta; y una norma ordena determinada conducta en tanto enlaza al comportamiento opuesto un acto coactivo como sanción”. Mientras el individuo que cumple la obligación que se le impone con una norma jurídica, acata la norma en cuestión, el individuo que, en caso de una violación del derecho, impone la sanción estatuida en la norma jurídica, aplica la norma jurídica; Ibíd. Págs. 129130 .

48. Ibíd. Pág. 123.

Revista de Ciencias Sociales - Número 65 (2014) - Universidad de Valparáíso - ISSN 0716-7725-Valparaíso, Chile 
Cuando Kelsen distingue la sanción civil de la penal, afirma que la primera intenta reparar el delito o ilicitud consistente en la conducta contra la cual se dirige esa sanción como reacción. Esta reparación consiste en que se pone término al estado provocado por la conducta ilícita, restableciéndose un estado conforme al derecho. Pero si bien este estado puede ser el mismo que debió haber sido obtenido mediante el comportamiento lícito, también puede ser otro que sirva como sustituto cuando el restablecimiento de ese estado ya no es posible ${ }^{49}$.

Esto podría explicar que cuando Kelsen caracteriza al derecho subjetivo en sentido técnico y, particularmente al poder que el orden jurídico confiere a su titular afirme que en caso de incumplimiento de la obligación, dicho poder es otorgado, indistintamente, el fin de:

(i) Hacer valer la falta de cumplimiento de la obligación, reclamar del (o por el) incumplimiento de la obligación, o reconocer la falta de cumplimiento del deudor ${ }^{50}$;

(ii) Hacer valer el cumplimiento de la obligación, hacer cumplir la obligación, u obtener el cumplimiento de una obligación jurídica pendiente ${ }^{51}$ y

(iii) Obtener la ejecución de la sanción, reclamar por el incumplimiento de la obligación a fin de que se dicte una sentencia estatuya una sanción concreta como reacción contra su incumplimiento de la obligación ${ }^{52}$, u obtener la realización de la sanción proclamada en la norma jurídica y atribuida a los hechos contrarios a derecho ${ }^{53}$.

49. En cambio, no es casi posible determinar el concepto de pena según su finalidad puesto que ella no proviene —o no proviene en forma inmediatadel contenido del orden jurídico; Ibíd. Pág. 124.

50. Ibíd. Págs. 147, 148, y 152.

51. Ibíd. Págs. 142, 147 y 152.

52. Ibíd. Págs. 147 y 149

53. KELSEN, Hans: Problemas capitales, cit. Págs. 507 y 539-540.

Facultad de Derecho y Ciencias Sociales - Universidad de Valparaíso - Chile 
Resulta entonces razonable concluir que cuando se hace referencia a la posibilidad de hacer valer el cumplimiento de la obligación o se utilizan expresiones semejantes, se apunta a la posibilidad de ejercitar una acción destinada a obtener, a través de la dictación de una sentencia judicial, la ejecución de la sanción civil, ya que ésta puede consistir en el cumplimiento de la obligación inicialmente incumplida o en otra conducta sustitutiva.

Esto podría explicar a quienes entienden que el poder con que cuenta el titular de un derecho subjetivo en sentido técnico sirve para exigir frente al Estado el cumplimiento del deber ${ }^{54}$, o a quienes consideran que afirmar que un individuo es titular de un derecho de este tipo equivale a afirmar que de la voluntad de ese individuo depende la exigibilidad coactiva de la obligación de otro ${ }^{55}$.

A diferencia de Kelsen, Hart no sólo descarta caracterizar al derecho subjetivo en términos de sanción sino que además prefiere mostrar la posición inicial de quien lo tiene mencionando, no el remedio procesal, sino la opción que aquél tiene abierta ante sí para hacer cumplir o no el correspondiente deber ${ }^{56}$. Para afirmar la existencia de un derecho subjetivo es, como hemos visto, suficiente y necesario que su titular tenga al menos algún grado control sobre la obligación correlativa ${ }^{57}$.

A primera vista, se podría decir que la diferencia apuntada no es más que una cuestión de énfasis. Aunque Kelsen no ponga el foco en el tipo de control que el titular del derecho subjetivo en sentido técnico tiene respecto de la conducta de su deudor (la opción de exigirle o no el cumplimiento de su deber) sino en la norma jurídica que lo faculta para reclamar frente al incumplimiento, la norma en cuestión hace que la ejecución de la sanción por dicho incumplimiento dependa de la voluntad de un individuo ${ }^{58}$. Y la sanción puede consistir precisamente en el cumplimiento de la obligación inicialmente incumplida.

54. CRUZ PARCERO, Juan Antonio: El lenguaje de los derechos, cit. Pág. 32.

55. ATRIA, F: “Existen los derechos sociales”. En: Doxa, Discusiones: Derechos sociales, $\mathrm{N}^{\circ}$ 4, 2004. Págs. 22 y 25.

56. HART, H.L.A: "Definición y teoría en la ciencia judicial”, cit, Pág. 117.

57. Ibíd:188.

58. KELSEN, Hans: Teoría pura del derecho, cit. Págs. 147-148.

Revista de Ciencias Sociales - Número 65 (2014) - Universidad de Valparáíso - ISSN 0716-7725-Valparáiso, Chile 
Tanto el concepto kelseniano de derecho subjetivo en sentido técnico como el concepto hartiano de derecho subjetivo se fundamentan en dos normas jurídicas diferentes: una norma regulativa (independiente para Kelsen y primaria para Hart) y una norma de competencia (no independiente para Kelsen y secundaria para Hart).

Cuando al titular de un derecho subjetivo reflejo conferido por una norma "independiente" 59 se le confiere, mediante una norma facultativa "no independiente" ${ }^{60}$, el poder de ejercitar una acción de reclamo frente al incumplimiento del deudor, ese individuo tiene, de acuerdo con Kelsen, un derecho subjetivo en sentido técnico.

A su turno, cuando, en virtud de una regla primaria ${ }^{61}$, un individuo $\mathrm{A}$ tiene frente a otro individuo $\mathrm{B}$ un deber $\mathrm{y}$, en virtud de una regla secundaria ${ }^{62}$, B tiene la opción de exigir que A cumpla o no cumpla con su deber y, por tanto, el poder de control sobre dicho cumplimiento, podemos decir que $\mathrm{B}$ tiene, de acuerdo con Hart, un derecho subjetivo ${ }^{63}$.

Esta coincidencia permite, sin embargo, captar dónde reside la diferencia y su importancia. Mientras Hart considera que sólo hay un

59. Una norma que obliga a cierta conducta enlazando a la contraria una sanción; Ibíd. Pág. 140.

60. Una norma que sólo determina una de las condiciones a las cuales una norma independiente enlaza el acto coactivo; Ibíd. Pág. 68.

61. Las reglas primarias prescriben que los seres humanos hagan u omitan ciertas acciones, lo quieran o no. Imponen deberes. Se refieren a acciones que implican movimiento o cambios físicos; HART, H.L.A.: El concepto de derecho, cit. Pág. 101.

62. Estas reglas dependen, en cierto sentido, de las reglas primarias, o son secundarias en relación con ellas. Establecen que los seres humanos pueden, haciendo o diciendo ciertas cosas, introducir nuevas reglas del tipo primario, extinguir o modificar reglas anteriores, o determinar de diversas maneras el efecto de ellas, o controlar su actuación. Confieren potestades, públicas o privadas. Prevén actos que conducen no simplemente a movimiento o cambio físico, sino a la creación o modificación de deberes u obligaciones; Ídem.

63. Sabido es que la contribución más relevante de "El concepto de derecho" —el trabajo más famoso de Hart— fue haber mostrado el poder explicativo de la unión o combinación de reglas primarias y secundarias para elucidar los conceptos

Facultad de Derecho y Ciencias Sociales - Universidad de Valparaíso - Chile 
concepto derecho subjetivo en sentido estricto (correlativo a una obligación) y que para afirmar su existencia es siempre necesario que su titular tenga al menos algún grado control sobre la obligación correlativa, Kelsen distingue dos tipos de derechos que son correlativos a obligaciones: el simple derecho reflejo y el derecho subjetivo en sentido técnico.

Esta distinción es relevante porque, de acuerdo con Kelsen, no es una función esencial del derecho objetivo estatuir derechos del segundo tipo sino tan sólo de una técnica específica del orden jurídico capitalista que ni siquiera domina en todas las partes de este orden sino

que constituyen la estructura del pensamiento jurídico. Uno de los conceptos que constituyen esta estructura es el de "derecho subjetivo", incluido por el propio Hart dentro del grupo de conceptos específicamente jurídicos que interesan profesionalmente al jurista y que son elucidados mejor en términos de la combinación de reglas primarias y secundarias; HART, H.L.A.: El concepto de derecho, cit. Págs. 102 y 121-122. Como apunta MacCormick, los derechos subjetivos — como Hart los describe - representan un "punto de cruce entre deberes y poderes". Quien tiene un derecho tiene el poder ejercitable, por sí mismo o por alguien en su nombre, de liberar o de exigir la realización de un acto que otro individuo deberá cumplir, de suerte que el deber (de actuar o de abstenerse de actuar) de ese otro individuo es condicional. Este parece ser el contenido mínimo — necesario y suficiente- para poder hablar de derecho subjetivo en clave hartiana, sin perjuicio de lo cual un derecho podría incorporar otros elementos. Concretamente, a esta fórmula podrían añadirse otros poderes que de hecho suelen concurrir, como cuando para el caso de incumplimiento de este deber condicional, el derecho otorga la opción de interponer una acción jurídica contra el obligado con el fin de obtener alguna compensación civil o de abstenerse de ejercitar este poder de interponer acciones; MACCORMICK, Neil: H.L.Hart. Marcial Pons, Madrid, 2010. (Trad. Juan Manuel Pérez Bermejo; original de1981) Pág. 184. Cabe llamar la atención sobre el hecho que MacCormick parece desinterpretar a Hart en un sentido importante pues mientras de lo dicho por éste se desprende que el punto de cruce entre deberes y poderes se produce por la confluencia de dos diferentes tipos de normas (primarias y secundarias), MacCormick parece entender que, de acuerdo con la versión hartiana de la teoría de la voluntad, el señalado punto de cruce encuentra fundamento en un solo tipo de norma que sería, al mismo tiempo, regulativa y de competencia. Esta interpretación es clara cuando, a propósito del análisis de los derechos de los niños como prueba en contra de la teoría de la voluntad, MacCormick señala que, desde la perspectiva de la teoría voluntarista de Hart, algunas normas que imponen deberes prevén que la ejecución por el titular del deber del acto o de la abstención requerido esté condicionada a la elección de alguna una persona; MACCORMICK, Neil; “Los derechos de los niños”, cit. Pág. 296.

Revista de Ciencias Sociales - Número 65 (2014) - Universidad de Valparáíso - ISSN 0716-7725-Valparaíso, Chile 
sólo en el terreno el denominado derecho privado ${ }^{64}$. Desde este punto de vista, la teoría de la voluntad no hace más que encubrir la defensa de una justificación extrajurídica para estatuir cierto tipo derecho subjetivo.

Desde una perspectiva como la de Hohfeld, tanto el poder de accionar frente al incumplimiento de la obligación de otro (característico del derecho subjetivo en sentido técnico) como el poder de control sobre la obligación de otro (propio del concepto hartiano de derecho subjetivo) admiten ser calificados como una especie de potestad ${ }^{65}$. Y en consecuencia, tanto el derecho subjetivo en sentido técnico como el concepto hartiano de derecho subjetivo pueden ser reconstruidos como una unión de los conceptos hohfeldianos de derecho subjetivo y potestad.

De otro modo no parece poder explicarse que Hohfeld afirme que el comprador de una cosa mueble que ha cumplido con todas las obligaciones que se derivan de una venta condicional, no tiene simplemente un "derecho" contractual a que el vendedor le transfiera el dominio de la cosa sino también, y con independencia de la voluntad del vendedor, la "potestad" de privar del dominio a éste y adquirir por su cuenta un título perfecto ${ }^{66}$. En este supuesto, no se vislumbra de qué manera el acreedor podría privar al vendedor de su dominio y obtener un título perfecto si no tuviera, con independencia de la voluntad del deudor, una acción para exigirle el cumplimiento de su obligación de transferirle el dominio ${ }^{67}$.

64. KELSEN, Hans: Teoría pura del derecho, cit. Págs. 147-149.

65. Digo una "especie" de potestad porque el concepto hohfeldiano de potestad no se reduce a las acciones procesales que persiguen el cumplimiento de un deber. Sobre este punto, ver por ejemplo, CRUZ PARCERO, Juan Antonio: "Leones, lenguaje y derechos", cit. Pág. 84 y ARRIAGADA, María Beatriz: "Los derechos sociales: Únicos derechos fundamentales". En: Aguilar, Gonzalo (Coord.): Derechos económicos, sociales y culturales en el orden constitucional chileno. Librotecnia, Santiago, 2012. Pág. 71.

66. Sin perjuicio de lo anterior, también se encuentran en una posición de "potestad", por ejemplo, los representantes designados para atender intereses patrimoniales, pues a ellos se le confieren potestades para modificar, con independencia de la voluntad de sus representados, ciertas relaciones jurídicas de éstos; HOHFELD, Wesley, ob. cit. Págs. 68-72.

67. ARRIAGADA, María Beatriz, ob. cit. Pág. 71.

Facultad de Derecho y Ciencias Sociales - Universidad de Valparaíso - Chile 
En la misma dirección apunta Atria cuando, apoyándose específicamente en la caracterización kelseniana del derecho subjetivo en sentido técnico, define el derecho subjetivo como la potestad de decidir si la obligación de otro será o no coactivamente exigida, y puntualiza estar empleando el concepto de potestad en el sentido de Hohfeld ${ }^{68}$. En este contexto aclara que no se trata de que el vendedor no tenga obligación de entregar la cosa, porque sabemos que esa obligación nace del contrato y no de la demanda del comprador; pero también sabemos que parte de lo que queremos decir al decir que el comprador tiene un derecho subjetivo es que el comprador tiene una potestad en sentido hohfeldiano, es decir, tiene un poder normativo para modificar la situación del otro, de suerte que la manifestación de voluntad del comprador es condición necesaria, aunque no suficiente, para que el derecho exija coactivamente al vendedor el cumplimiento de su obligación ${ }^{69}$.

El hecho que el concepto de derecho subjetivo defendido por la llamada teoría de la voluntad pueda ser reconstruido a partir de dos conceptos hohfeldianos diversos (derecho subjetivo y potestad) pone claramente de manifiesto la magnitud del error en que incurren quienes pretenden que el concepto hohfeldiano de derecho subjetivo corresponde a la posición de quien tiene el poder de entablar una acción legal de reparación en el caso que el obligado no cumpla con su obligación, o a la posición de quien tiene un poder de control sobre la obligación de otro $^{70}$. Pero quienes asumen que el derecho subjetivo

68. ATRIA, Fernando, ob. cit. Pág. 22, y nota N $^{\circ} 19$ del mismo trabajo.

69. Ibíd. Págs. 22-23.

70. Este mal entendido conduce a conclusiones derechamente absurdas. Laporta, por ejemplo, entiende que en la relación jurídica denotada por este concepto, el sujeto que se encuentra en la posición activa dispone de una "acción” para exigir ("claim"). Como consecuencia, entre las posiciones jurídicas activas identificadas por Hohfeld sólo una, la de libertad, sería parafraseable en términos deónticos estrictos. Ninguna de las otras (incluyendo la de derecho subjetivo) sería definible en términos de esa naturaleza; LAPORTA, Francisco: "Sobre el concepto de derechos humanos". En: Doxa, 4, 1987. Pág. 26. Esto es absurdo desde el momento en que el propio Hohfeld insiste en que el derecho subjetivo se define como el correlativo de un deber. Por otra 
hohfeldiano es un interés o beneficio jurídicamente protegido incurren en el mismo tipo de error.

Como destaca Kelsen, en la definición según la cual el derecho subjetivo es determinado como un interés jurídicamente protegido, se expresa en forma especialmente clara el dualismo característico de la ciencia jurídica tradicional consistente en contraponer el derecho en sentido subjetivo al derecho en sentido objetivo. Si el derecho en sentido objetivo es un sistema de normas y el derecho subjetivo es algo enteramente diferente como lo es el interés, no cabría subsumir bajo el mismo concepto superior tanto al derecho objetivo como al subjetivo. Un derecho subjetivo no puede ser entonces un interés protegido por el derecho sino solamente la protección de ese interés. Y esa protección consiste en que el orden jurídico estatuye una obligación jurídica de no lesionar ese interés enlazando a su lesión una sanción. Un derecho subjetivo no es otra cosa que el reflejo de esa obligación ${ }^{71}$.

Lo anterior muestra que aunque MacCormick crea que la teoría de la voluntad se equivoca en la medida en que, al considerar que los poderes de renuncia o exigencia (aun atribuidos precisamente en defensa de los derechos) son constitutivos esenciales de éstos, confunde el derecho sustantivo con disposiciones adjetivas ${ }^{72}$, la teoría que él defiende se equivoca de modo semejante.

Desde su perspectiva, hay una diferencia significativa entre afirmar que todo niño debe ser nutrido, educado y, si es posible, amado, y afirmar que todo niño tiene derecho al cuidado, la nutrición y al amor. Y las razones que esgrime para justificar esa diferencia parecen indicar, como el propio MacCormick lo señala, la posibilidad de que los derechos sean o puedan ser lógicamente anteriores a los deberes ${ }^{73}$. El

parte, es contradictorio afirmar que la posición de derecho subjetivo no es definible en términos deónticos y que, en cambio, sí lo es la posición de libertad. Ésta es, de un lado, correlativa a la posición de "no derecho", la cual es opuesta a la posición de derecho subjetivo; de otro lado, es opuesta a la posición de deber, la cual es correlativa a la de derecho subjetivo.

71. KELSEN, Hans: Teoría pura del derecho, cit. Págs. 145-146.

72. MACCORMICK, N. 1988 (1975): 297.

73. Ibíd. Págs. 298-301.

Facultad de Derecho y Ciencias Sociales - Universidad de Valparaíso - Chile 
reconocimiento de un derecho implica la imposición de deberes a otras personas distintas del titular del derecho, y no al revés, al punto que cuáles sean y sobre quién han de recaer estos deberes es un asunto de cuya cuidadosa definición depende que el derecho sea garantizado de la mejor forma posible ${ }^{74}$.

A juicio de MacCormick, reconocer a todos los miembros de una clase el derecho a cierto trato significa presuponer que, en circunstancias normales, ese trato es un bien para todos los miembros de esa clase y que sería injusto privar de ese trato a algún miembro de esa clase ${ }^{75}$. Pero al decir esto pasa por alto que la consideración de que cierto trato es un bien (o un interés) para todos los miembros de una clase, justifica el reconocimiento de un derecho a ese trato.

Como conferir un derecho es proteger un interés, es decir, obligar a otro u otros a no lesionar el interés que el derecho protege, la teoría según la cual los derechos subjetivos son intereses jurídicamente protegidos también encubre, como la teoría de la voluntad, la defensa de una razón extrajurídica para el otorgamiento de ciertos derechos subjetivos.

\section{El fundamento del modelo de análisis hohfeldiano de las posiciones jurídicas subjetivas}

En la sección anterior se ha podido mostrar que tras la discusión teórica que aparentemente versa sobre el significado que debe atribuirse al concepto hohfeldiano de derecho subjetivo se oculta el enfrentamiento de dos teorías diferentes acerca del fundamento extra-jurídico de los derechos subjetivos, en la medida en que ambas teorías encubren la defensa de una justificación extrajurídica para estatuir derechos subjetivos.

Aunque se ha podido mostrar de qué manera, frente a esta discusión, parece imponerse la claridad con la que el propio Hohfeld definió el concepto de derecho subjetivo, se debe poner de relieve por

\footnotetext{
74. Ibíd. Pág. 302.

75. Ídem.
}

Revista de Ciencias Sociales - Número 65 (2014) - Universidad de Valparáíso - ISSN 0716-7725-Valparaíso, Chile 
qué, desde la perspectiva del modelo de análisis hohfeldiano de las posiciones jurídicas subjetivas, ninguna de estas teorías podría contar como una explicación de lo que los derechos subjetivos son, con independencia de las razones extra-jurídicas que justifican su otorgamiento.

En la primera sección de este trabajo, dedicada a caracterizar el modelo de análisis hohfeldiano de las posiciones jurídicas, se mencionó que éste podía identificarse como un ejercicio de "elucidación conceptual" o "análisis conectivo" debido a que la comprensión apropiada de cada uno de los conceptos comprendidos en la explicación se obtiene mediante la captación sus relaciones con los demás conceptos del mismo sistema.

A continuación se mostró que las ocho diversas posiciones jurídicas subjetivas se identifican y distribuyen en dos diferentes grupos, sobre la base de dos importantes distinciones provenientes de la teoría analítica del derecho: (i) normas regulativas y normas de competencia y (ii) actos materiales y actos normativos.

Una mirada atenta del ejercicio analítico de Hohfeld permite captar que, en cada uno de los dos grupos, hay un solo concepto que puede ser comprendido sin referencia a otro concepto del mismo sistema. El concepto de deber, en el primer grupo y el concepto de potestad, en el segundo. Lo que ambos conceptos tienen en común es que, a diferencia de todos los otros, pueden explicarse con referencia a una acción del sujeto que se encuentra en la situación que el concepto designa.

Quien tiene un deber se encuentra en la exigencia de realizar o no realizar una acción. Mientras el titular de un derecho subjetivo, sólo se encuentra en la posición correlativa de un deber y en la opuesta a un no derecho. No es necesario referirse a acción alguna para describir esta posición puesto que es puramente pasiva. A su turno, un privilegio o libertad no es otra cosa que el correlativo de un no derecho y el opuesto de un deber, y un no derecho es únicamente el correlativo de un privilegio y el opuesto de un derecho subjetivo. La relación de privilegiono derecho se fundamenta precisamente en la ausencia de una norma que imponga un deber y confiera un derecho subjetivo.

La posición de potestad se caracteriza porque su titular tiene la posibilidad de realizar o no realizar una acción. La posición de sujeción

Facultad de Derecho y Ciencias Sociales - Universidad de Valparaíso - Chile 
puede ser, en cambio, descrita sin referencia a acción alguna porque, al igual que la posición de derecho subjetivo, es puramente pasiva: es el correlativo de una potestad y el opuesto de una inmunidad. Ésta última, es por su parte, solamente el correlativo de una incompetencia y el opuesto de una sujeción, mientras la posición de incompetencia no es más que el correlativo de una inmunidad y el opuesto de una potestad. La relación de inmunidad-incompetencia se fundamenta en la ausencia de una norma de competencia que confiera una potestad e imponga una sujeción.

Sobre lo dicho cabe efectuar dos observaciones:

(i) La mayoría de los conceptos del esquema explicativo de Hohfeld sólo puedan captarse con exclusiva referencia a sus opuestos y correlativos; y

(ii) Si bien los conceptos de deber y de potestad también pueden captarse con referencia a una acción del sujeto que se encuentra en la posición que cada concepto designa, ninguno de ellos puede definirse como una acción. Un deber es la "exigencia" de realizar o no realizar una acción, y una potestad es la "posibilidad" de realizar una acción.

Se puede entonces advertir que frente a la discusión acerca del sentido que debe atribuirse al concepto hohfeldiano de derecho subjetivo, no sólo se impone la claridad con la que Hohfeld definió este concepto, sino también el fundamento mismo de su modelo de análisis: distinguir las relaciones puramente jurídicas de los hechos físicos y psíquicos que las hacen $\operatorname{surgir}^{76}$. Por ello es que, entre otras razones, la explicación hohfeldiana de las posiciones jurídicas subjetivas puede ser considerada un ensayo de jurisprudencia analítica ${ }^{77}$.

\footnotetext{
76. HOHFELD, Wesley, ob. cit. Pág. 31.

77. CARRIÓ, Genaro: "Nota preliminar”. En: Hohfeld, Wensley: Conceptos jurídicos fundamentales. Fontamara, México D.F., 1992 (original de 1913). Págs. 19-20.
}

Revista de Ciencias Sociales - Número 65 (2014) - Universidad de Valparáíso - ISSN 0716-7725-Valparaíso, Chile 
En palabras del propio Hohfeld:

"Aunque esta sugestión inicial puede parecer muy obvia, los argumentos que se escuchan casi a diario en los tribunales, y también un número considerable de fallos, suministran prueba amplia de la infortunada e inveterada tendencia a confundir y mezclar los elementos jurídicos y los no jurídicos en un problema dado" 78 .

A juicio de Hohfeld, las asociaciones a ideas involucradas en los dos conjuntos de relaciones — la relación física y psíquica, por una parte y la puramente jurídica, por la otra- son, según la naturaleza misma del caso, muy cercanas. Y este hecho habría ejercido necesariamente una marcada influencia sobre las doctrinas generales y las reglas específicas de los sistemas primitivos del derecho así como en el derecho medieval ${ }^{79}$. Por otra parte, buena parte de la ambigüedad y falta de precisión de la terminología jurídica tendría su origen en el hecho que muchas de nuestras palabras sólo eran originariamente aplicables a cosas físicas, de modo que su uso en conexión con relaciones jurídicas es, estrictamente hablando, figurativo o ficticio ${ }^{80}$.

Desde este punto de vista, ninguna teoría que confunda las relaciones puramente jurídicas con los hechos físicos y psíquicos que las hacen surgir, puede contar como una explicación de lo que los derechos subjetivos son, con independencia de las razones extra-jurídicas que justifican su otorgamiento.

78. HOHFELD, Wesley, ob. cit. Pág. 31. Los énfasis son míos.

79. Ibíd: 31-32.

80. Ibíd: 32-37. Como ejemplos de este uso metafórico de palabras tomadas en préstamo del mundo físico se mencionan, por ejemplo, "transferir", "poder" y "libertad".

Facultad de Derecho y Ciencias Sociales - Universidad de Valparaíso - Chile 


\section{BIBLIOGRAFÍA CITADA}

ALCHOURRÓN, Carlos y BULYGIN, Eugenio: "Definiciones y normas”. En: Análisis lógico y derecho, CEPC, Madrid, 1991 (original de1983). Págs. 439-463.

ALEXY, Robert: Teoría de los derechos fundamentales, CEPC, Madrid, 2007 (Trad. Carlos Bernal Pulido; original de 1984).

ARRIAGADA, María Beatriz: "Los derechos sociales: Únicos derechos fundamentales". En: Aguilar, Gonzalo (Coord.): Derechos económicos, sociales y culturales en el orden constitucional chileno. Librotecnia, Santiago, 2012. Págs. 61-91.

ATIENZA, Manuel y RUIZ MANERO, Juan: Las piezas del derecho, Ariel, Barcelona, 2004.

ATRIA, Fernando: "Existen los derechos sociales". En: Doxa, Discusiones: Derechos sociales, $N^{\circ}$ 4, 2004. Págs. 15-59.

BULYGIN, Eugenio: "Sobre las normas de competencia". En: Alchourrón, C. y Bulygin, E.: Análisis lógico y derecho. CEPC, Madrid, 1991 (original de 1988). Págs. 485-498.

CARRIÓ, Genaro: "Nota preliminar”. En: Hohfeld, Wensley: Conceptos jurídicos fundamentales. Fontamara, México D.F., 1992 (original de 1913).

CRUZ PARCERO, Juan Antonio:

__ "Leones, lenguaje y derechos. Sobre la existencia de los derechos sociales (Réplica a Fernando Atria), en Doxa, Discusiones: Derechos sociales, $\mathrm{N}^{\circ}$ 4, 2004. Págs.71-98.

_ El lenguaje de los derechos. Ensayo para una teoría estructural de los derechos. Trotta. Madrid, 2007.

FERRAJOLI, Luigi: Principia iuris. Teoría del derecho y de la democracia. Trotta, Madrid, 2011 (Trad. Perfecto Ibáñez, Juan Carlos Bayón, Marina Gascón, Luis Prieto Sanchís y Alfonso Ruiz Miguel; original de 2007).

FINNIS, John: Ley natural y derechos naturales. Abeledo Perrot, Buenos Aires, 2000 (Trad. Cristóbal Orrego; original de 1980).

GUASTINI, Riccardo: Distinguiendo. Estudios de teoría y metateoría del derecho, Gedisa, Barcelona, 1999 (Trad. Jordi Ferrer; original de 1996). 
HART, H.L.A.:

___ "Definición y teoría en la ciencia judicial". En: Derecho y moral. Contribuciones a su análisis. Depalma, Buenos Aires 1962 (Trad. Genaro Carrió; original de 1953). Págs. 93-130.

__ "Legal Rights". En: Essays on Bentham. Studies in Jurisprudence and Political Theory. Oxford University Press, New York, 1982.

_- El concepto de derecho. Abeledo-Perrot, Buenos Aires, 2009 (Trad. Genaro Carrió; original de 1961).

HOHFELD, Weseley: Conceptos jurídicos fundamentales, Fontamara, México D.F., 1992 (Trad. Genaro Carrió; original de 1913).

KELSEN, Hans:

__ Problemas capitales de la teoría jurídica, Porrúa, México D.F., 1987 (Trad. Wenceslao Roces; original de1923).

—_ Teoría pura del Derecho, (2 ${ }^{a}$ edición), Porrúa, México D.F., 1991 (Trad. Roberto Vernengo; original de 1960).

LAPORTA, Francisco: "Sobre el concepto de derechos humanos". En: Doxa, 4, 1987. Págs. 23-46.

MACCORMICK, Neil:

- "Los derechos de los niños: una prueba de fuego para las teorías de los derechos". En: Anuario de Filosofía del Derecho, $\mathrm{N}^{\circ}$ 5, Madrid, 1988. (Trad. Mercedes Carreras y A. Luis MartínezPujalte; original de 1975).

—— H.L.Hart. Marcial Pons, Madrid, 2010. (Trad. Juan Manuel Pérez Bermejo; original de1981).

—_ Instituciones del derecho. Marcial Pons, Madrid, 2011. (Trad. Fernando Atria y Samuel Tschorne; original de 2007).

MORESO, Josep Joan y VILAJOSANA, Josep María: Introducción a la teoría del derecho. Marcial Pons, Madrid, 2004.

NINO, Carlos: Introducción al análisis del derecho. Astrea, Buenos Aires, 1980.

RAZ, Joseph:

—_ Razón práctica y normas. CEPC, Madrid, 1991 (Trad. Juan Ruiz Manero; original de 1975).

—_La ética en el ámbito público. Gedisa, Barcelona, 2001 (Trad. Juan Ruiz Manero; original de1994).

ROSS, Alf: “Sobre los conceptos de 'Estado' y ‘Órganos del Estado’ en Derecho Constitucional”. En: El concepto de validez y otros

Facultad de Derecho y Ciencias Sociales - Universidad de Valparaíso - Chile 
ensayos. Fontamara, México, 1991 (Trad. Eduardo A. Vásquez; original de1961). Págs. 73-92.

SEARLE, John:

- La construcción de la realidad social. Paidós, Barcelona, 1997 (Trad. Antoni Domènech; original de 1995).

—_ Actos de habla. Ensayo de Filosofía del Lenguaje. Cátedra, Madrid, 2007 (Trad. Luis Valdés Villanueva; original de 1969).

STRAWSON, Peter: Análisis y metafísica, Paidós, Barcelona, 1997. (Trad. Nieves Guasch; original de 1992).

WITTGENSTEIN, Ludwig: Investigaciones filosóficas. Crítica, Barcelona, 2008 (Trad. Alfonso García Suárez y Ulises Moulines; original de 1953). 